\title{
Design Evolution and Verification of the A-3 Chemical Steam Generator
}

\author{
Casey Kirchner \\ NASA, Stennis Space Center, MS 39529
}

\begin{abstract}
Following is an overview of the Chemical Steam Generator system selected to provide vacuum conditions for a new altitude test facility, the A-3 Test Stand at Stennis Space Center (SSC) in Bay St. Louis, MS. A-3 will serve as NASA's primary facility for altitude testing of the $\mathrm{J}-2 \mathrm{X}$ rocket engine, to be used as the primary propulsion device for the upper stages of the Ares launch vehicles. The Chemical Steam Generators (CSGs) will produce vacuum conditions in the test cell through the production and subsequent supersonic ejection of steam into a diffuser downstream of the J-2X engine nozzle exit. The Chemical Steam Generators chosen have a rich heritage of operation at rocket engine altitude test facilities since the days of the Apollo program and are still in use at NASA White Sands Test Facility (WSTF) in New Mexico. The generators at WSTF have been modified to a degree, but are still very close to the heritage design. The intent for the A-3 implementation is to maintain this heritage design as much as possible, making minimal updates only where necessary to substitute for obsolete parts and to increase reliability. Reliability improvements are especially desired because the proposed system will require 27 generators, which is nine times the largest system installed in the 1960s. Improvements were suggested by the original design firm, Reaction Motors, by NASA SSC and NASA WSTF engineers, and by the A-3 test stand design contractor, Jacobs Technology, Inc. (JTI). This paper describes the range of improvements made to the design to date, starting with the heritage generator and the minor modifications made over time at WSTF, to the modernized configuration which will be used at A-3.
\end{abstract}

The paper will discuss NASA's investment in modifications to SSC's E-2 test facility fire a full-scale Chemical Steam Generator in advance of the larger steam system installation at A-3. Risk mitigation testing will be performed in early 2009 at this test facility to verify that the CSGs operate as expected. The generator which will undergo this testing is of the most recent A-3 configuration, and will be instrumented far in excess of what is normally required for operation. The extra data will allow for easier troubleshooting and more complete knowledge of expected generator performance. In addition, the early testing will give SSC personnel experience in operating the CSG systems, which will expedite the process of installation and activation at A-3.

Each Chemical Steam Generator is supported by a complement of valves, instruments, and flow control devices, with the entire assembly called a "module." The generators will be installed in groups of three, historically called "units". A module is so called because of its modular ability to be replaced or serviced without disturbing the other two modules installed on the same unit. A module is pictured in Figure 1, shown with its generator secured by white bands in its shipping (vs. installed) configuration. The heritage system at WSTF is composed of a single unit (three generator modules), pictured in Figure 2 as it was installed in 1965. In contrast, A-3 will have nine units operating in 
parallel to achieve vacuum conditions appropriate for testing the J-2X engine. Each of the combustors operates in two modes and achieves the so-called "full-steam" mode after all three of its stages ignite. Ignition of the first stage is achieved by exciting a spark plug; the second stage and main stage are lit by the flame front of the previous stage. The main stage burns approximately $97 \%$ of the total propellant flow and uses the heat energy to vaporize water into superheated steam. While the main stage remains unlit, the combustor is in so-called "idle" mode. In the WSTF system, this idle mode is not optimized for water usage, and does not need to be, as the water is pumped from a large reservoir. The water supply at A-3 will be contained in tanks with finite volume, so water optimization is preferred for the modernized configuration. Multiple solutions for this issue have been proposed, with the leading concept being a change to the operational definition of "idle mode," with the generator running in a lower heat flux condition. 


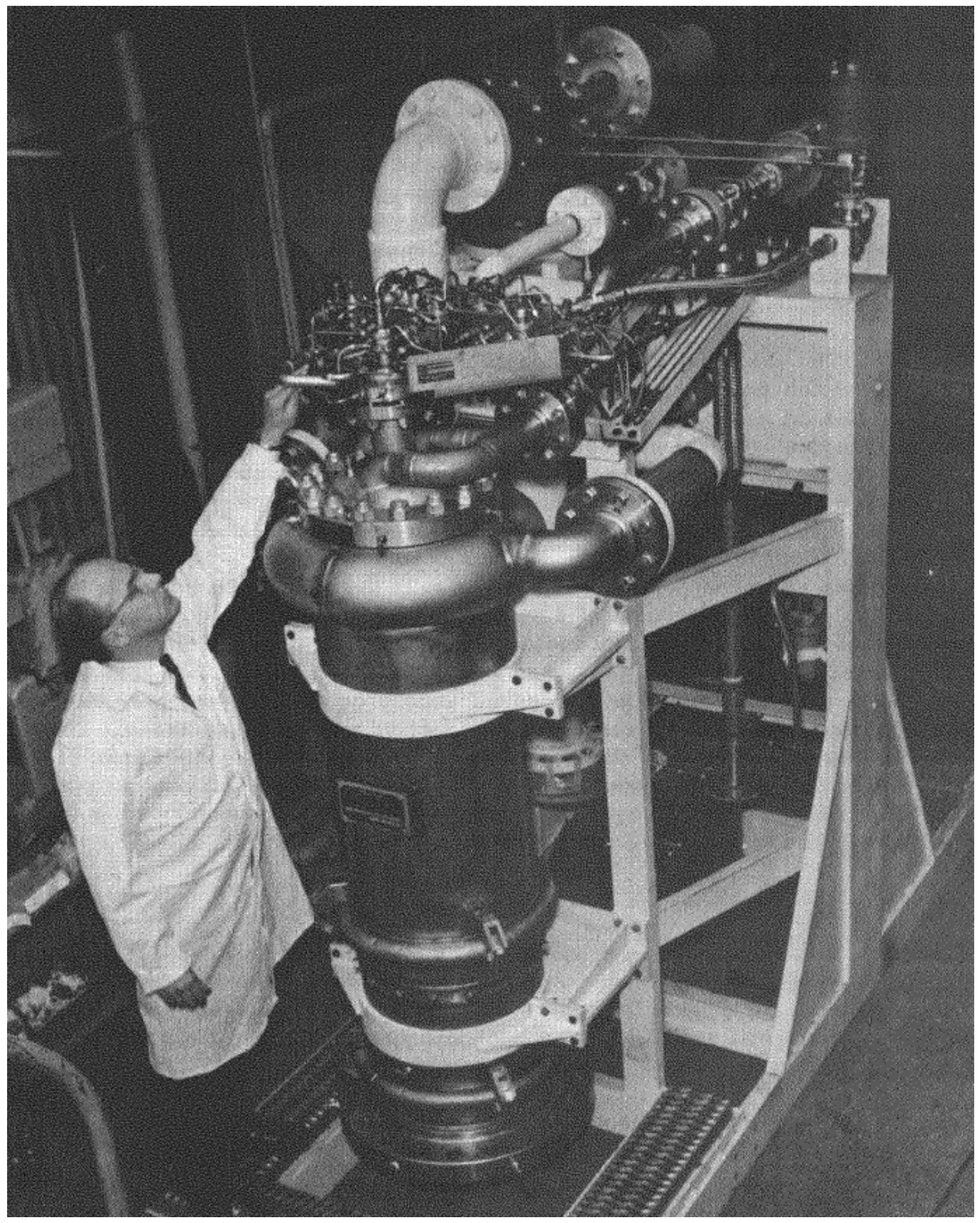

Figure 1: Chemical Steam Generator Module (credit Reference 4) 


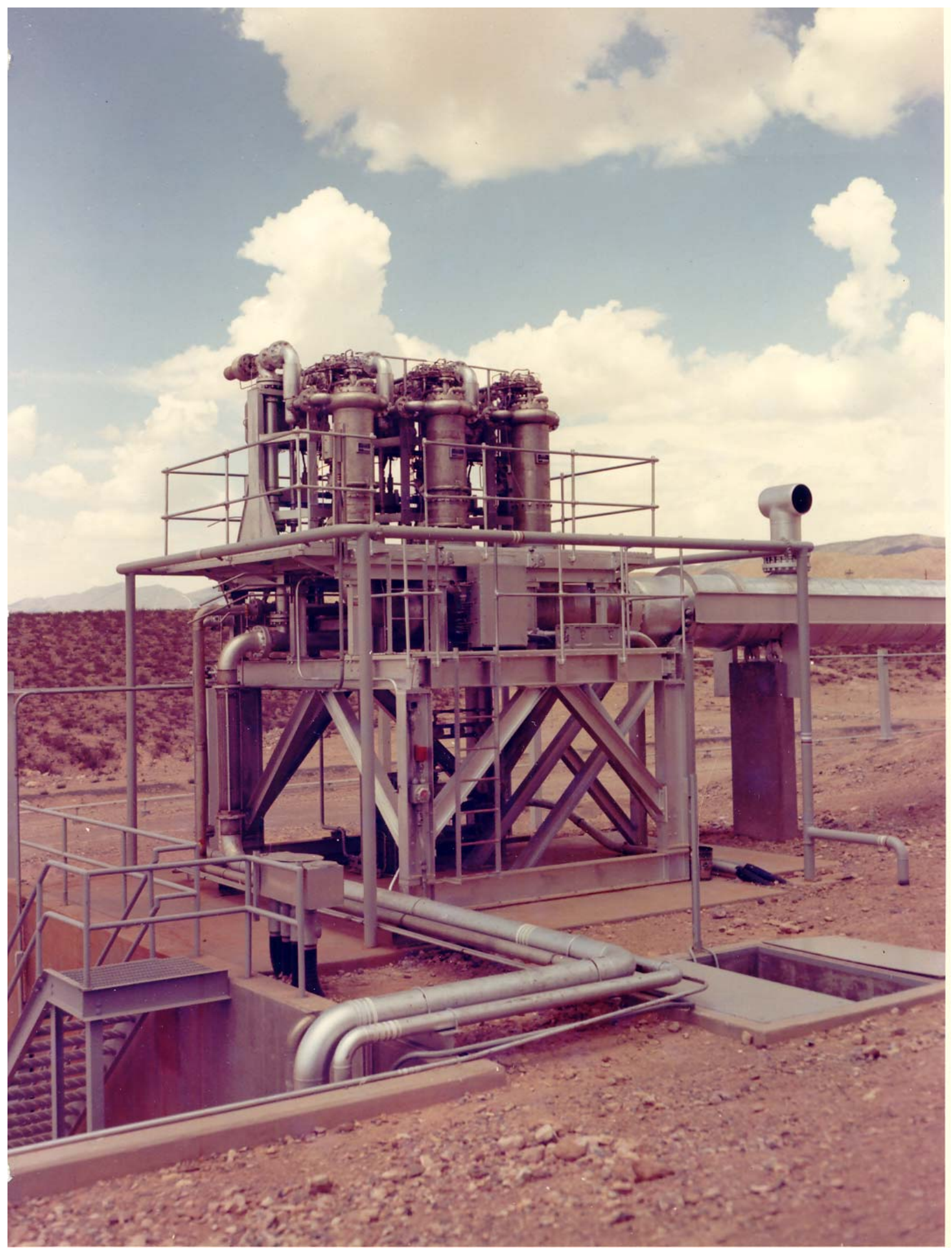

Figure 2: Chemical Steam Generator Unit, as installed at WSTF in the 1960's (credit Reference 3)

An unquantified amount of vibration is produced by the heritage system while the generators are firing. This vibration contributes to two resulting problems - there are several joints which must be re-tightened with much higher frequency than other joints - 
a rate that may be unsustainable at a larger-scale facility like A-3; also, pressure and temperature switches which feed data into the relay control system are sometimes "unlatched," initiating undesirable shutdowns of the steam system. This vibration has never been measured, but the WSTF water venturis were relocated several years ago to a new location which resulted in a noticeable decrease in the rate of such pressure-switch shutdowns. Additional venturi modifications have been incorporated into the A-3 design which should further decrease vibrational effects.

Another key design problem is the method of control. Historically, the CSGs have been controlled by relay logic, with inputs from pressure and temperature switches. In addition to the aforementioned undesirable shutdowns, another consequence of using switches is that there is not a large data set of operational parameters available to fully characterize performance of the CSGs. In order to better monitor the operation and health of such a large system at A-3, an update to transducer instruments and PLC control is planned. During system activation, operators will further have the advantage of being able to quickly change the firing sequence through programming, rather than changes in hardware settings.

Based on years of operating in cramped quarters, WSTF engineers recommended spacing the CSG modules further apart to provide easier access to components. Two additional feet were added between each module, which resulted in a lengthening of the manifolds which feed propellant to and carry steam from the modules. This presented additional issues in terms of thermal flexibility design. Specifically, the steam plenum supports the weight of all three generators, but not of the main valves which supply the propellant. With a greater expansion under temperature due to extra material, the flexible pipe segments which connect the main valves to the generators had to be redesigned. In the case of the propellants, flex hoses were lengthened. In the case of the water inlets, flexible couplings were added to join grooved hard pipe segments. These changes produce an additional benefit of further vibration damping.

Activation of the E-2 testbed facility will begin in December 2008, and fabrication of the A-3 generators began in October 2008. Commencement of testing, interpretation of data and evaluation of the new design is scheduled for March 2009.

\section{References:}

1. "LOX / Alcohol Chemical Steam Generator: Modification History and Recommendations," Carl Kastner, Reaction Motors, LLC, 2007.

2. "CSGS Operating Sequence and Control System Drawings," Carl Kastner, Reaction Motors, LLC, 2007.

3. "INSTALLED PHOTOS of 3 MODULE CSGS at TRW \& NASA-WSTF and PUMP SYSTEM at NASA-WSTF," Carl Kastner, Reaction Motors, LLC, 2007. 
4. "Operation and Maintenance Manual, Altitude Simulation System for White Sands Missile Range - Publication No. 0724-M1," Thiokol Chemical Corporation, Reaction Motors Division, year unknown.

5. "WJI PROP-ALT-0106.G - LARGE ALTITUDE SIMULATION SYSTEM OPERATIONS,” Mike Barrett, HTSI, LASS Test Conductor at WSTF, 2005.

6. "WJI PROP-ALT-0036.B - ALTITUDE SIMULATION SYSTEM DETAILED MAINTENANCE PROCEDURE," Mike Barrett, HTSI, LASS Test Conductor at WSTF, 2004. 